\title{
El desarrollo alternativo: misión de la Universidad de Nariño para la vida y la paz ${ }^{1}$
}

\author{
The alternative development: mision of the Nariño \\ University for the life and peace
}

\section{O desenvolvimento alternativo: missão da universidade de Narinho para a vida e para a Paz}

La Universidad de Nariño, desde su autonomía y concepción democrática y en convivencia con la región sur de Colombia, forma seres Humanos, ciudadanos y profesionales en las diferentes áreas del saber y del conocimiento con fundamentos éticos y espíritu crítico para el desarrollo alternativo en el acontecimiento mundo. ${ }^{2}$

Misión, Universidad de Nariño

La Universidad de Nariño, entendida como un acontecimiento en la cultura, es reconocida por su contribución, desde la creación de valores humanos, a la paz, la convivencia, la justicia social y a la formación académica e investigativa, comprometida con el desarrollo regional en la dimensión intercultural. ${ }^{3}$

Visión, Universidad de Nariño

María Elena Erazo Coral $^{4}$

Universidad de Nariño, Colombia

https://orcid.org/0000-0002-2295-4564

Recepción: 20/02/2020

Evaluación: 18/05/2020

Aceptación: 28/05/2020

Artículo de Investigación- Reflexión

https://doi.org/10.19053/01227238.11958

\section{RESUMEN}

El objetivo: Reflexionar sobre el desarrollo alternativo que contribuye a la vida y a la paz de la región como proyecto misional de la Universidad de Nariño en el escenario de la Asamblea Universitaria. La originalidad de la investigación radica en abordar el tema desde la lógica regional para pensar sus singularidades, pues de las múltiples misiones institucionales, unas pretenden aportar y resolver los problemas del capital y del mercado, y otras, como es el caso de la UDENAR,

1 Este artículo es de reflexión y presenta el resultado de la investigación "Las Reformas de la Universidad de Nariño, 1972 y 2009", financiada por la Universidad de Nariño.

2 Acuerdo . $^{\circ} 035$ de 15 de marzo de 2013 por el cual se adopta el Proyecto Educativo Institucional (PEI) de la Universidad de Nariño.

3 Ibíd., 20.

4 Doctora en Ciencias de la Educación de la Universidad de Nariño. Pertenece al Grupo de Investigación Edu-Multiverso, y actualmente es docente de la Universidad de Nariño, línea de investigación estudios regionales. Correo electrónico: merazocoral@gmail. com. 
buscan contribuir al buen vivir y a la paz de la región a través del desarrollo alternativo. Método: Esta investigación se aborda desde la metodología de la no simultaneidad de lo simultáneo, por tanto, la estrategia utilizada es el análisis de las fuentes bibliográficas y de archivo a través de una matriz que establece las particularidades regionales y locales que descentren la mirada de los análisis homogeneizantes y universales, lo cual permite concluir: la Universidad de Nariño, a través de la Asamblea Universitaria, construye bajo los principios de autonomía y democracia una misión y una visión para el desarrollo alternativo que conlleva un compromiso por y para la vida y la paz.

Palabras clave: Autonomía universitaria; desarrollo alternativo; paz, región.

\section{ABSTRACT}

The objective Reflect on the alternative development that contributes to life and peace in the Region as a missionary project of the University of Nariño on the stage of the University Assembly. The originality of the research lies on approaching the issue from the regional logic to reflect upon its singularities, because there are multiple institutional missions, some of them look for contributing and solving the problems of capital and the market, and others, as the UDENAR case, they seek to contribute to the quality of life and peace of the region through the alternative development. Method: This research focused from the methodology of the non-simultaneity of the simultaneous, therefore the strategy applied is the bibliographic and archive sources analysis through a matrix that establishes the regional and local particularities that focus the gaze of the homogenizing and universal inquiries, which allows to conclude: The University of Nariño, through the University Assembly, builds a mission and vision for alternative development under the principles of autonomy and democracy that entails a commitment to and for life and peace.

Key words: University autonomy; alternative development; peace; region; University of Nariño.

\section{RESUMO}

O objetivo: refletir sobre o desenvolvimento alternativo que contribui para a vida e para a paz da Região como projeto e missão da Universidade de Narinho no cenário da Assembleia Universitária. A originalidade da pesquisa se encontra na abordagem do tema a partir da lógica regional para pensar suas singularidades, pois há múltiplas missões institucionais, umas pretendem contribuir e resolver os problemas do capital e do mercado, e outras, como é o caso da UDENAR, buscam contribuir para o bem viver e para a paz da região através do desenvolvimento alternativo. Método: esta pesquisa se constrói a partir da metodologia da simultaneidade do simultâneo, portanto a estratégia utilizada é a análise das fontes bibliográficas e de arquivo por meio de uma matriz que estabelece as particularidades regionais e locais que descentram a perspectiva da análise homogeneizantes e universais, o que permite Concluir: a Universidade de Narinho, através da Assembleia Universitária constrói sob os princípios de autonomia e democracia uma missão e visão para o desenvolvimento alternativo que envolve um compromisso com a vida e com a paz.

Palavras-chave: Autonomia universitária; desenvolvimento alternativo; Paz; Região; Universidade de Narinho. 


\section{INTRODUCCIÓN}

Pensada como el ingreso a un orden establecido por el sistema capitalista, la modernidad integra en ese orden a los miembros de la sociedad creando diversas instituciones, entre ellas la universitaria, que produce, a través de los códigos de cada una de las ciencias y disciplinas, nuevas subjetividades, valores, perspectivas de vida; la educación universitaria es, por esa razón, tan preponderante para un país; hace parte de su proyecto de sociedad.

En este sentido, desde los centros de poder se ha marcado un proyecto claro para la educación universitaria, consignado en documentos como el Plan París (1998), el Plan Bolonia (1999), los lineamientos del Banco Mundial para la educación en América Latina o los de la Organización para la Cooperación y el Desarrollo Económicos (OCDE), que pretenden hacer de la educación una mercancía, además de estar al servicio del gran capital, políticas que han sido asumidas por el Estado colombiano ${ }^{5}$.

Para el neoliberalismo, si bien la educación pública es vista como una necesidad, lo es por ser un dispositivo que permite la formación de sujetos que aportan a la acumulación de capital; por ello se pretende que la universidad sea reglamentada por la ley de la oferta y la demanda, es decir, que se asuma como parte del mercado. Este propósito se hace evidente cuando el Estado genera políticas que llevan a la desfinanciación y posterior mercantilización de la universidad.

Así, al verse enfrentadas a tal situación, las universidades públicas de Colombia tienen la opción de seguir los lineamientos descritos o la de asumir una posición crítica y pensar en una misión y visión distintas, ejerciendo su derecho a la democracia y a la autonomía universitaria consagrada en la Constitución.

La Universidad de Nariño opta por esto último. En efecto, en ejercicio de este derecho de rango constitucional, crea un espacio de participación democrática denominado Asamblea Universitaria, en el cual se encuentran profesores, estudiantes y trabajadores para discutir, pensar y construir la misión y visión de la institución. En los debates se plantean múltiples formas de concebir la universidad y, teniendo en cuenta las condiciones locales y regionales dentro de las cuales actúa esta alma máter se llega a establecer que desde este lugar se debe crear una universidad alternativa para aportar a la construcción de una región alternativa y, el camino para lograrlo es proponer y asumir una misión que posibilite procesos que lleven al desarrollo alternativo, una de las claves para la construcción del buen vivir y la paz.

El artículo se desarrolla a partir de tres temáticas: en la primera, se pone de manifiesto cómo la modernidad y el logo eurocéntrico y estadocéntrico se impone frente a formas diversas de habitar el mundo, hecho que excluye e invisibiliza todo aquello que no esté dentro de sus fronteras, lo cual favorece los

5 Acuerdo n. 2034 de 2014 o Ley de Inspección y Vigilancia de 2015, Decreto 2450 de 2015. Políticas de COLCIENCIAS para la Investigación y Evaluación de Investigadores, libros y revistas. Políticas del Consejo Nacional de Acreditación, https://www.mineducacion.gov.co/1621/articles-344500_archivopdf_sintesi_doc_acuerdosuperior.pdf 
procesos de violencias vividos en Colombia. La segunda, aborda la posición de la Universidad de Nariño en el espacio de la Asamblea Universitaria frente a las posturas epistemológicas occidentales y propone el debate, la reflexión y la creación de nuevos lugares de pensamiento que permitan ejercer las funciones misionales desde una perspectiva que favorezca el desarrollo alternativo, elemento fundamental para aportar al buen vivir y a la paz. La tercera, hace un análisis sobre la relación universidad y región en función de pensarse como universidad alternativa y región alternativa; de allí la construcción de una misión y visión institucional que plantean el desarrollo alternativo por y para la vida y la paz.

La metodología de trabajo se realiza desde los presupuestos conceptuales expuestos por Carlos Rincón Bolívar en su libro La no simultaneidad de lo simultáneo. Posmodernidad, globalización y culturas en América Latina:

Lo no simultáneo son las diversas respuestas a esa necesidad, dentro de la heterogeneidad y diversidad de las sociedades latinoamericanas. La ficción latinoamericana es determinante dentro del debate posmoderno internacional. Hoy por hoy, el análisis y la teorización de los nuevos procesos culturales y la teoría cultural son el terreno por excelencia del debate sobre lo posmoderno en Latinoamérica, o para ser más preciso: la forma más actual de enfrentar la discusión y el diagnóstico sobre la contemporaneidad. En la tensión entre simultaneidades y no simultaneidad, el grado de dificultad de autopercepción y determinación de una posición propia para quienes buscan estructurar procesos dentro de los que se hallan inscritos resulta redoblado. Ese el hecho real del que se trata de dar cuenta dentro del debate latinoamericano sobre el posmodernismo, con el cumplimiento de rituales de proclamar el atraso informativo, la condición periférica y la babeización de los lenguajes. ${ }^{6}$

Estos postulados permiten construir una metodología que piensa las particularidades, la heterogeneidad, la diversidad de los procesos culturales que se suceden en los ámbitos local y regional, descentrando así la mirada del análisis hegemónico y universal que propone la episteme moderna. Bajo los planteamientos de la no simultaneidad de lo simultáneo se abordan las lecturas y análisis de los documentos de archivo que reposan en la Universidad de Nariño sobre el proceso de reflexión, debate y construcción de la misión y visión institucional. Trabajos como este aportan a los estudios regionales, línea de investigación en la cual se inscribe este trabajo.

\section{La modernidad, la universidad, la exclusión y la violencia}

La universidad, aunque fue creada en el siglo XII, se reinventa entre los siglos XX y XXI pues nuevas realidades como la división del trabajo, nuevos niveles de enseñanza, emergencia del libro como fenómeno social, las comunicaciones, proceso de globalización, el aumento poblacional y por tanto el incremento en

6 Carlos Rincón Bolívar, La no simultaneidad de lo simultáneo. Posmodernidad, globalización y culturas en América Latina (Bogotá: Universidad Nacional de Colombia, 1995), 226. 
los márgenes de consumo exigen de la universidad cambios ${ }^{7}$ que respondan a la propuesta de sociedad moderna.

Así, es necesario entender el concepto de modernidad para comprender el papel que dentro del sistema capitalista se le asigna a las universidades, pues la modernidad no es otra cosa que el ingreso a un orden y en ese nuevo orden se coloca a la ciencia como elemento fundamental para transformar la realidad social; y en ese sentido impone la racionalidad occidental como la única forma de ver, de pensar, de existir en el mundo; las otras racionalidades entran en la categoría de incivilizadas, irracionales, bárbaras, es decir, la complejidad que existe en la sociedad se reduce a una sola manera de existencia y esa es la que cabe en las categorías creadas por la ciencia social occidental: "civilizado", "ciudadano", "hombre", "blanco" y el mismo concepto de "ciencia" cierra sus puertas a saberes distintos a los occidentales.

La universidad se constituye, entonces, en una institución fundamental para la creación de ese nuevo orden, de ese nuevo ser humano, de las nuevas subjetividades que requiere el mundo capitalista, pues a partir de allí se construye modernidad, es decir. se crea un sistema ideológico, una episteme, un orden encaminado a fortalecer ese mundo para la acumulación de riquezas, y en eso la universidad juega un papel fundamental porque esos postulados que se inventan desde ese lugar se reconocen como "ciencia", es decir, como "verdaderos", "objetivos", "científicos", "neutrales", razón por la cual se cierra toda posibilidad de incluir allí otros saberes, tales como los ancestrales de comunidades como la indígena, la campesina, la afro, generando por tanto, desde esta institución, una violencia que Aníbal Quijano ha denominado la violencia simbólica ${ }^{8}$, o Pierre Bourdieu y Loïc Wacquant llaman "imperialismo cultural", a partir de lo cual es posible las otras violencias, de género, económicas, ideológicas, políticas, sociales ${ }^{9}$.

¿Qué tiene que ver esto con la paz?, ¡mucho!, pues esta forma de ver y pensar el mundo desde la lógica occidental o moderna hizo que se invalidara, que se invisibilizara, que se violentara a los hombres y mujeres reales, de carne y hueso, que habitan esta nación llamada Colombia, este sur occidente del país donde existen comunidades que ocupan un territorio y tienen otros saberes, otras cosmovisiones, otras lógicas de ver, hablar y habitar el mundo que en las lógicas y en el orden mundial y nacional se niegan y, por tanto, no tienen lugar en la universidad, pues el orden cultural y científico occidental desacreditó y suprimió "todas las prácticas sociales de conocimiento que contrariasen los intereses a los que servía"10, hecho conocido como un "epistemicidio".

7 Jorge Eliécer Ruiz, “Crítica de la universidad”, ECO. Revista de la cultura de Occidente vol. 12-3, n. 69 (1966).

8 Aníbal Quijano, “Colonialidad del poder y clasificación social”, en Epistemologías del Sur (Perspectivas), eds. Boaventura de Sousa Santos y María Paula Meneses (España: Akal, 2014), 67-107.

9 Pierre Bourdieu y Loïc Wacquant, Las argucias de la razón imperialista (Barcelona: Paidós, 2001), 7-9.

10 Boaventura de Sousa Santos y María Paula Meneses, “Introducción”, en Epistemologías del Sur (Perspectivas), 8. 
En esto consistió el espistemicidio, es decir, la supresión de los conocimientos locales perpetrada por un conocimiento alienígena. Bajo el pretexto de la "misión colonizadora" el proyecto de colonización procuró homogenizar el mundo, obliterando las diferencias culturales. La consecuencia fue el desperdicio de mucha experiencia social y la reducción de la diversidad epistemológica, cultural y política del mundo. En la medida en que sobrevivieron esas experiencias y esa diversidad fueron sometidas a la norma epistemológica dominante: fueron definidas $-y$ muchas veces acabaron autodefiniéndose - como saberes locales y contextuales utilizables en apenas dos circunstancias: como materia prima para el avance del conocimiento científico y como instrumentos de gobierno indirecto, inculcando en los pueblos y prácticas dominados la ilusión creíble de que se gobernaban por sí mismos. La pérdida de una autorreferencia genuina no sólo fue una pérdida gnoseológica sino también y sobre todo, una pérdida ontológica: la de saberes inferiores propios de seres inferiores. ${ }^{11}$

Así, el proyecto de nación sobre el cual se levanta Colombia es un proyecto de la modernidad que excluye; de este modo era imposible no enfrentarse a la guerra que se vivió por más de medio siglo en el país, pues indígenas, campesinos, afros, hombres y mujeres que pensaban distinto, que creían y soñaban con la construcción de una sociedad diferente a la que les proponían los centros de poder y el Estado colombiano no tuvieron cabida en ese proyecto de nación, en ese proyecto de Estado-moderno y, de este modo, como dice Hernán Henao, era imposible no vivir una, dos y las múltiples violencias que ha vivido Colombia.

Un país ha insistido en convertirse en nación, durante 100 años de gestión política
centralista, pero que ni en los años 30 ni en los 60 logró reconocerse país de regiones
y país de complejos culturales regionales; con unas clases sociales en el poder que
se han negado a reconocer la heterogeneidad social y cultural del colombiano, tiene
que estar condenado a sufrir una y dos y quizá más violencias "fratricidas". Nunca,
o casi nunca, en tiempos presentes, el reconocimiento del otro como diferente y
su consiguiente aceptación, ha estado en la mentalidad intolerante - en términos
económicos, sociales, políticos, ideológicos y religiosos - de los colombianos. ${ }^{12}$

El antropólogo Hernán Henao (1945-1999) fue asesinado por pensar, por decir cosas como estas, y es que el "ideal" de modernidad propuesto por los centros de poder lleva a principios del siglo XX a proponer el concepto de progreso, y a mediados del siglo la teoría de desarrollo, que no es otra cosa que la de plantear una sola fórmula mediante la cual la sociedad puede ser feliz, y es la de seguir los lineamientos que señalen los centros de poder en el marco de los Estados nacionales modernos. Esta fue la construcción de una nación que nunca reconoció la heterogeneidad social y cultural de Colombia, que no supo reconocer al otro y se volvió intolerante frente a la diferencia. Esta visión de nación

\footnotetext{
11 Ibíd.

12 Hernán Henao, "La dimensión cultural en los estudios de las localidades", en La restructuración de las ciencias sociales en América Latina, ed. Santiago Castro Gómez (Bogotá: Centro Editorial Javeriano, 2000), 71.
} 
moderna, excluyente, no podía esperar cosa distinta a la violencia, esa violencia o violencias que nos acompañan con mayor severidad hace más de cincuenta años, mostrándonos con hechos ciertos y crueles dejados por la guerra que la fe de los científicos sociales en el progreso era imposible de consolidar justamente porque excluye, violenta e invisibiliza realidades locales y regionales.

\begin{abstract}
Entonces, el conocimiento cierto que nos habian prometido los científicos sociales apareció como una consecuencia de su fe en el progreso: hallaba expresión en la creencia en constantes mejoras, que serían obra de expertos, proceso en el cual el estado que las "permitía" desempeñaría un papel clave en el esfuerzo por reformar la sociedad. Se esperaba que las ciencias sociales acompañaran ese proceso de mejora racional y gradual, y de ahí parecía seguirse que las fronteras del estado fueran vistas como el marco natural dentro del cual se darían tales mejoras. ${ }^{13}$
\end{abstract}

Y es que esta forma de concebir la nación desde un logo estadocéntrico, se sustenta en las teorías de la modernidad, del progreso y el desarrollo; este último se inaugura con el discurso de Harry S. Truman en el seno de las Naciones Unidas en el año de 1945, reunidas con el objetivo de diseñar políticas y medidas concretas "para el desarrollo económico de los países subdesarrollados"14, de tal forma que esto fue lo que plantearon:

Hay un sentido en el que el progreso económico acelerado es imposible sin ajustes dolorosos. Las filosofías ancestrales deben ser erradicadas; las viejas instituciones sociales tienen que desintegrarse; los lazos de casta, credo y raza deben romperse; y grandes masas de personas incapaces de seguir el ritmo del progreso deberán ver frustradas sus expectativas de una vida cómoda. Muy pocas comunidades están dispuestas a pagar el precio del progreso económico (United Nations, 1951). ${ }^{15}$

Estos discursos que niegan las diferencias culturales e históricas de los pueblos latinoamericanos necesitan ser incorporados en las mentalidades de los pueblos, requieren que los hombres y mujeres de carne y hueso crean que el desarrollo es la única opción de existencia, pretenden que se convenzan de la necesidad de acabar con las tradiciones, con las culturas ancestrales, con las cosmovisiones distintas a las propuestas por los poderosos del mundo, por eso "[...] las filosofías ancestrales deben ser erradicadas; las viejas instituciones sociales tienen que desintegrarse; los lazos de casta, credo y raza deben romperse". ¿Qué es esto? La puesta en marcha de una violencia institucionalizada.

La pregunta en este momento es ¿qué papel juega la universidad en ese proyecto de sociedad, de nación? Como se dijo anteriormente, es el de crear ese nuevo hombre que ame la modernidad, que ame el desarrollo, que menos-

13 Immanuel Wallerstein, coord., Abrir las ciencias sociales. Informe de la Comisión Gulbenkian para la restructuración de las ciencias sociales (México: Siglo Veintiuno Editores / UNAM, 2007), 88-89.

14 Arturo Escobar V., La invención del Tercer Mundo. Construcción y deconstrucción del desarrollo (Bogotá: Grupo Editorial Norma, 1998), 20.

15 Citado en Escobar, La invención. 
precie todo lo que sea diferente, distinto, vale decir, que menosprecie a quienes conserven sus lazos sociales ancestrales, sus filosofías, pues estos deben ser catalogados y categorizados como "subdesarrollados"; la academia, la universidad ayudó mucho a instalar esta doctrina, especialmente las ciencias sociales que acompañaron a este discurso creando "conceptos científicos" y binarios como civilizado/incivilizado, cultura/barbarie, hombre/mujer, desarrollo/subdesarrollo.

El sistema capitalista necesita instituciones que aporten a la construcción de ese nuevo orden, por eso la universidad se moderniza a partir del siglo XIX, porque a esta se le asigna el poder de crear, re-crear, sustentar y difundir las nuevas prácticas discursivas que lo sustentan. Hoy el discurso neoliberal en apariencia cambia, pero en esencia busca: universalizar, globalizar, crear capital y volver mercado y mercancía aquello que en el siglo XX aún no lo era: salud, educación, cultura; por eso, en el plan Bolonia se dice: [...] que la validez y eficacia de una civilización se puede medir a través del atractivo que tenga su cultura para otros países... necesitamos asegurarnos de que el sistema de educación superior europeo adquiera un grado de atracción mundial igual al de nuestras extraordinarias tradiciones culturales y científicas ${ }^{16}$.

De tal suerte que el dominio y estructura del sistema fundamentado en el mercado y el capital se levanta sobre la base de imponer un solo referente cultural y científico como el europeo; por eso, Pierre Bourdieu y Loïc Wacquant afirman que este es el "poder de universalizar los particularismos vinculados a una tradición histórica", pero, con la argucia de presentar estas singularidades como si fueran universales, utilizan mecanismos tendientes a convencer que la realidad es única gracias a los "coloquios universitarios, a los libros de éxito, a las revistas semi especializadas, a los informes de expertos, de los balances de comisiones a las portadas de revistas...", porque "[...] están presentes en todas partes simultáneamente, desde Berlín a Tokio y desde Milán a México, y cuentan con poderoso apoyo y el refugio de esos lugares supuestamente neutros que son los organismos internacionales..."17 como el Banco Mundial o la OCDE.

En estos términos, es imperioso decir claramente que la universidad que actúa desde la lógica eurocéntrica y estadocéntrica le sirve a los propósitos de los centros de poder, al mercado y al capital. Por eso la pregunta que hoy debe hacerse la universidad es ¿al servicio de quién va a desarrollar sus funciones misionales? ¿Hay posibilidad de generar propuesta de universidad distinta a la que proponen los centros de poder a través del Banco Mundial y la OCDE y el Estado colombiano? ¿Es posible crear elementos para que la universidad aporte a la solución de problemas reales de las regiones en las cuales ejerce su tarea? ¿Es posible que la Universidad de Nariño encuentre rutas distintas para aportar a la construcción de los tejidos sociales resquebrajados en las últimas décadas por la

\footnotetext{
16 "Declaración de Bolonia", Declaración conjunta de los ministros europeos de Educación (Bolonia, 1999), http://eees.umh.es/contenidos/Documentos/DeclaracionBolonia.pdf. (3 de junio, 2020).

17 Bourdieu y Wacquant, Las argucias, 7-9.
} 
guerra? ¿Es posible pensar en una universidad cuya misión y visión aporten a desarrollos alternativos para y por la vida y la paz?

Un proyecto de universidad para desarrollos alternativos por y para la vida y la paz

Los conceptos de modernidad, progreso o desarrollo no solo son cuerpos teóricos de las ciencias sociales, son propuestas que generan realidades concretas, por eso es necesario que los profesores y estudiantes que habitan la universidad pública colombiana reflexionen sobre el papel que la universidad cumplirá en este tiempo que se ha firmado el "Acuerdo final para la terminación del conflicto y la construcción de una paz estable y duradera"18, que pretende poner fin a un conflicto armado de más de medio siglo en Colombia; en este documento se concibe la paz como un proceso que se construye a través de la puesta en marcha de una serie de acciones, políticas y reformas que involucran no solo al Estado sino a la sociedad civil.

Las situaciones de violencia que se viven en el mundo, y concretamente en Colombia, han motivado una serie de estudios que dotan a la paz de un marco teórico con categorías de análisis para entender las violencias y los posibles caminos que conducen a la paz. Justamente una de esas categorías clasifica a la paz como negativa, positiva e imperfecta y trasformadora. La paz negativa "se refiere a la relación directa de esta con la ausencia de enfrentamientos armados"; en tal sentido, "es válido decir que, paradójicamente, desde la concepción que define la paz como antítesis a la guerra es posible justificar, legitimar y asumir principios y lógicas propias de la guerra en aras de la paz"19. La paz positiva lleva a la resolución de conflictos desde la sinergia. "De ese modo, la justicia social se manifiesta como elemento fundamental para la paz". La paz imperfecta y trasformadora concibe la paz como un proceso inacabado por tanto en constante construcción ${ }^{20}$; es en esta última categoría que se inscribe el acuerdo de paz firmado entre el gobierno colombiano y las Farc.

En ese camino por construir una sociedad en paz se asigna papel preponderante a la educación, pues la paz también se entiende como una construcción colectiva que está directamente relacionada con la democracia, hecho que indica madurez de una sociedad lo cual garantiza el respeto de los derechos humanos. El logro de una sociedad que vive la democracia debe ser respaldada por el trabajo formativo de la educación como política social ${ }^{21}$. En tal sentido, en la Universidad de Nariño, la democracia se constituye como uno de los principios institucionales porque es "la forma de habitar la Universidad y en el mundo de manera participativa, responsable, solidaria y sin discriminación alguna"22.

18 Presidencia de la República de Colombia, "Acuerdo final para la terminación del conflicto y la construcción de una paz estable y duradera” (La Habana, 2016) https://www.cancilleria.gov.co/sites/default/files/Fotos2016/12.11 1.2016nuevoacuerdofinal.pdf. (10 de octubre, 2018).

19 Esteban A. Ramos, Paz transformadora (y participativa), citado en Eddy Javier Paz Maldonado y Wilmer Nahán Díaz Pérez, "Educación para la paz: Una mirada desde la Universidad Nacional Autónoma de Honduras", Innovación educativa 19, n. 79 (2019) 177.

20 Paz y Díaz, "Educación para la paz", 177.

21 Ibíd.

22 Acuerdo n. ${ }^{\circ} 035$ de 15 de marzo de 2013. 
Es decir, los procesos misionales de docencia, investigación e interacción social deben desarrollarse bajo el principio de la democracia, y desde luego, bajo el principio de autonomía pues es deber de la universidad reflexionar de manera autónoma sobre su misión para asumir el papel que le corresponde en ese camino que conduzca al país a vivir en paz.

La democracia y la autonomía posibilitan pensar la ciencia desde lugares distintos a los propuestos por el logo estadocéntrico que "construían el marco, supuestamente evidente, dentro del cual tenían lugar los procesos analizados por las ciencias sociales, [en tal sentido] ...se daba por sentado que las estructuras sociales modernas estaban en los estados modernos... [por eso] El concepto de 'desarrollo', que fue el concepto clave después de 1945, se refería ante todo, y sobre todo, al desarrollo de cada estado tomado como unidad individual" ${ }^{23}$.

Esa "unidad individual", que avala un cuerpo discursivo llamado "ciencia" no permite incorporar al sistema científico, y por tanto al sistema universitario, los saberes de hombres, mujeres, campesinos, indígenas, comunidad afro del país y, en concreto, del sur occidente colombiano, saberes que la ciencia moderna asume como bárbaros e incivilizados, pero que sí ha tenido la astucia, en tiempos neoliberales, de convertir el patrimonio cultural forjado durante siglos, en mercancía y capital y hacer del derecho a la salud, a la educación, a una cultura propia, elementos que se compran y se venden ${ }^{24}$.

Imagen 1. Patrimonio wayuu convertido en mercancía ${ }^{25}$
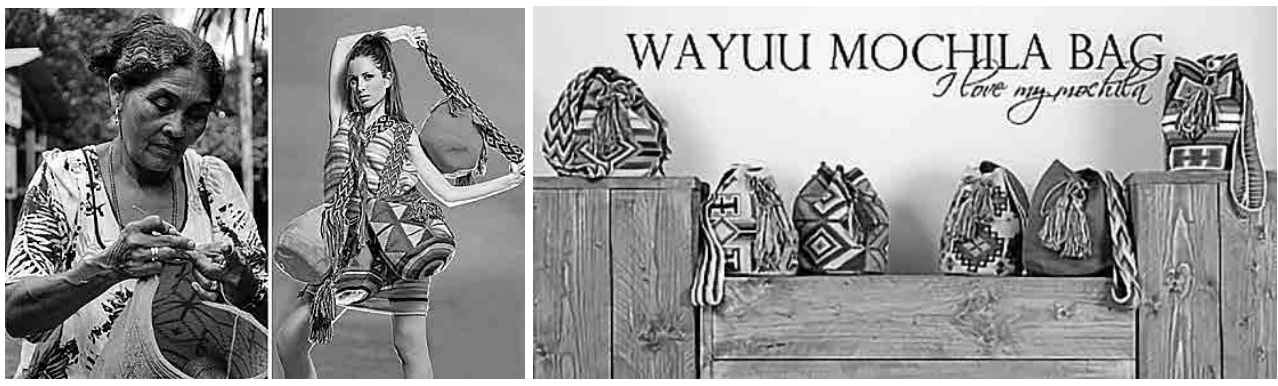

Fuente: https://www.las2orillas.co/wayuu-bag -asi-se-roban-nuestro-patrimoniocultural

23 Wallerstein, Abrir las ciencias sociales, 87-88.

24 "Creamos una empresa para comercializar artesanías". Frase de los hermanos Tomás y Jerónimo Uribe, sobre su negocio en las Islas Vírgenes. "http://www.lapatria.com/politica/creamos-una-empresa-para-comercializar-artesanias-30306 (6 de octubre, 2017).

25 Karmen Ramírez Boscán, "Wayuu Bag: un negocio redondo a costa del patrimonio cultural”, Las 2 Orillas (25 de marzo, 2015). https://www.las2orillas.co/wayuu-bag -asi-se-roban-nuestro-patrimonio-cultural/. 
Imagen 2. Las marcas multinacionales usufructúan los diseños ancestrales ${ }^{26}$

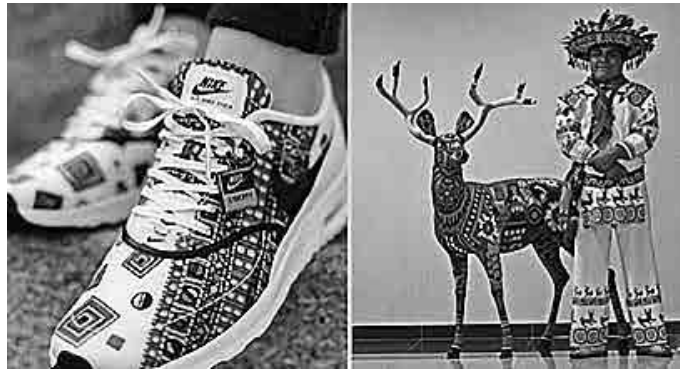

Fuente: https://www.pinterest.de/pin/459507968216318725/?nic_v2=1a2kjo2lo

Frente a la venta de la educación como mercancía hay serios documentos y estudios ${ }^{27}$ que dan cuenta de cómo ese proceso se realiza de manera indirecta, vía desfinanciación de la universidad pública y venta de servicios; por eso, hoy más que nunca, necesitamos hacer acopio de la autonomía universitaria, derecho consagrado en la Constitución Colombiana, “[...] para contrarrestar críticamente las presiones de la economía de mercado y las ideologías que pretendan desviar su función o actuar a favor de terceros" 28 .

El concepto de autonomía universitaria es una reivindicación del movimiento estudiantil de Córdoba, en Argentina (1918), que busca cambios en:

El Régimen administrativo, el método docente y el concepto de autoridad; por ello exigen calidad en la enseñanza relacionada directamente con la calidad de los docentes y piden el concurso docente y la libertad de cátedra; reclaman autonomía y democracia universitaria manifiesta en la eliminación de los cargos vitalicios y en la recomposición de los órganos de gobierno con participación de docentes y estudiantes. ${ }^{29}$

Según la investigación de Olmedo Vargas, estas ideas se expanden en Colombia en la década de los veinte del siglo pasado, difundidas por, en aquellos años, el estudiante Germán Arciniegas en la revista Universidad ${ }^{30}$. Sin embargo, es en las décadas de los sesenta a ochenta cuando la lucha por la autonomía universitaria toma fuerza y logra elevar este derecho a mandato constitucional

26 "Nike se piratea el diseño de los indígenas huicholes, según para ayudarlos a 'promocionar' su cultura". http://www.denunciasmx. com/2016/05/nike-se-piratea-el-diseno-de-los.html (10 de junio, 2017).

27 Boaventura de Sousa Santos, La Universidad en el siglo XXI. Para una reforma democrática y emancipatoria de la universidad (Bolivia: Plural Editores, 2007).

28 Acuerdo $n .^{\circ} 035$ de 15 de marzo de 2013.

29 María Elena Erazo Coral, "Nuevos sentidos de la Reforma de Córdoba: El caso de la Universidad de Nariño", Revista Historia de la Educación Latinoamericana 20, n. ${ }^{\circ} 30$ (2018).

30 Gabriel David Samacá y Álvaro Acevedo Tarazona, “De la reforma de Córdoba al Cordobazo. La universidad como escenario de las luchas por la democracia en Argentina 1918-1969 y su impacto en Colombia”, Memorias, n. ${ }^{\circ} 15$ (2011): 185. 
en el año de 1991, consagrado en los artículos 68 y 69 y refrendado en la Ley General de Educación de 1992, en su artículo $28^{31}$.

En el año 2008, en la Universidad de Nariño, el principio de autonomía:

Se erige como condición necesaria para la creación de ciencia, la comprensión de los saberes como conocimiento humano, el ejercicio de la libertad como esencia de la búsqueda incesante de respuestas a las incertidumbres y, para la confluencia de los propósitos misionales: docencia, investigación e interacción social.

La Universidad de Nariño, en la dinámica de su función misional, tiene la facultad de definir y trazar sus políticas para incentivar la investigación como el ejercicio libre de creación de conocimiento. La autonomía preservará la naturaleza de la interacción social para contrarrestar críticamente las presiones de la economía de mercado y las ideologías que pretendan desviar su función o actuar a favor de terceros. $^{32}$

Haciendo uso de este derecho, a través del Acuerdo 079 de noviembre del $2010^{33}$, el Honorable Consejo Superior de esta institución crea la Asamblea Universitaria:

ARTÍCULO 34. Asamblea Universitaria. La Asamblea Universitaria es un espacio de participación y deliberación de los estamentos universitarios con reconocimiento Institucional. Funciona en ejercicio de los principios constitucionales de democracia participativa y autonomía universitaria; manifiesta las más altas aspiraciones de la sociedad por la defensa y adecuada financiación de la universidad pública. El rector expedirá el correspondiente reglamento para su composición y funcionamiento. ${ }^{34}$

Fue justamente en el seno de este organismo, y haciendo uso de los principios de autonomía y democracia participativa, que se estudiaron y debatieron distintos paradigmas, misiones, visiones, objetivos y principios para luego establecer cuál es la universidad que quieren profesores, trabajadores y estudiantes, al servicio de quién y para qué se enseña, se investiga y, por tanto, quién sacará provecho de esos saberes. Es evidente entonces que la Universidad de Nariño no asume de manera pasiva las teorías y políticas que impone el pensamiento eurocéntrico ni estadocéntrico; todo lo contrario, la propuesta de universidad que se gesta es distinta a la visión moderna, globalizada, desarrollista.

31 Erazo Coral, "Nuevos sentidos", 74-75.

32 Plan de Desarrollo 2008-2020, "Pensar la Universidad y la Región” (San Juan de Pasto: Universidad de Nariño, 2008).

33 Acuerdo 079 de noviembre de 2010 por el cual se adopta la Reforma Universitaria como una política académico-administrativa institucional, para dar cumplimiento al Plan de Desarrollo de la Universidad de Nariño 2008-2020, "Pensar la Universidad y la Región" (San Juan de Pasto, 2010).

34 Ibíd. 
Imagen 3. Reuniones de la Asamblea Universitaria ${ }^{35}$

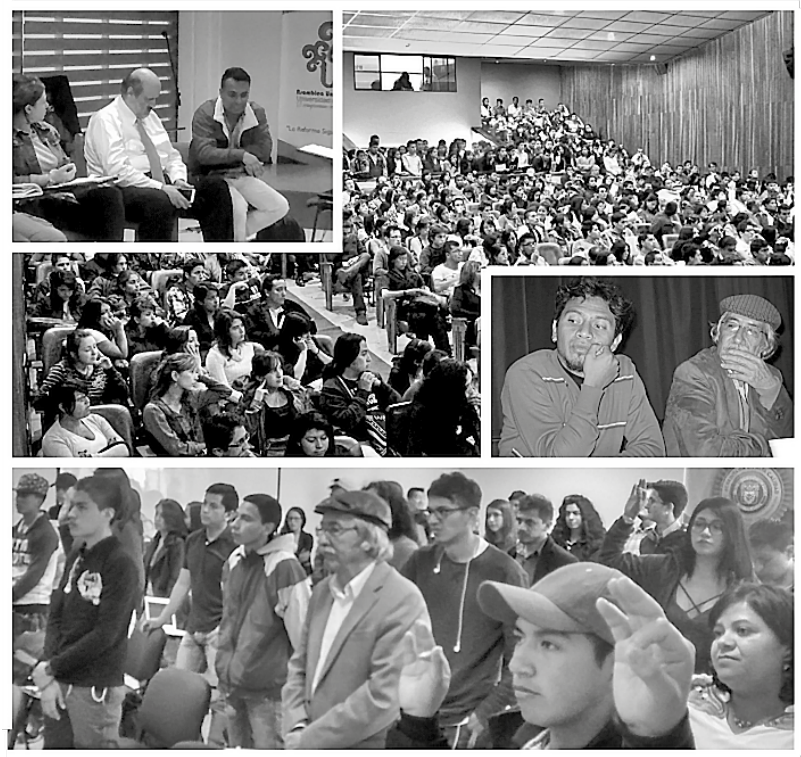

Fuente: Universidad de Nariño. Archivo de la Reforma Universitaria, 2009-2016.

Quienes habitan la Universidad de Nariño no se quedan en la crítica y en la denuncia de las políticas para la educación superior en los ámbitos nacional e internacional, sino que logran construir una contrapropuesta a esa mirada que se expresa en la Misión Institucional a través de proponer el concepto de desarrollo alternativo: "La Universidad de Nariño, desde su autonomía y concepción democrática y en convivencia con la región sur de Colombia, forma seres Humanos, ciudadanos y profesionales en las diferentes áreas del saber y del conocimiento con fundamentos éticos y espíritu crítico para el desarrollo alternativo en el acontecimiento mundo"36.

Pues uno de los grandes objetivos de la Reforma Universitaria y del proceso asambleario es pensar una universidad para la región, para los hombres y mujeres que la habitan, que reconozca sus saberes, sus cosmovisiones, su pensamiento, razón por la cual el concepto de desarrollo alternativo es vital en la propuesta misional:

El propósito fundamental de la reforma es contribuir a la reflexión teórica sobre desarrollo alternativo, entendido como un mejor vivir de toda la comunidad. Esto implica un modelo de organización social donde la lógica de los medios, de más

35 Porción media superior: Sesión plenaria en el auditorio Luis Santander Benavides. Arriba a la izquierda: Taller con Leopoldo Múnera como invitado especial. En el centro, a la derecha: Julián Sabogal Tamayo y Juan Pablo Córdoba, miembros de la Mesa Directiva de la Asamblea Universitaria. Abajo: Toma de juramento en posesión de asambleístas (San Juan de Pasto: Universidad de Nariño, 2013-2017).

36 Acuerdo n. ${ }^{\circ} 035$ de 15 de marzo de 2013 por el cual se adopta el Proyecto Educativo Institucional (PEI) de la Universidad de Nariño (San Juan de Pasto, 2013). 
productos y más construcciones, se cambie por la lógica de los fines, de tal manera que en el centro de todos los propósitos se sitúe el ser humano, entendido como comunidad no como individuo. Una condición sine qua non para tales logros es pensar con cabeza propia, como dijera Simón Rodríguez: creamos o erramos. Se trataría de construir pensamiento propio, entendido como una construcción compleja e hibridada que no rechace los aportes de la ciencia europea, leída críticamente, y que integre de manera creativa, los aportes de los ancestros, tanto indígenas como afro descendientes. ${ }^{37}$

En tal sentido, pensar la región a partir de la categoría del desarrollo alternativo no significa rechazar los aportes de la ciencia europea, lo que rechaza categóricamente es la violencia que esta genera cuando invalida y excluye los saberes producidos en este sur occidente de Colombia, saberes que durante siglos han producido los indígenas y los afrodescendientes, los campesinos, en fin, los hombres y las mujeres de esta región. Exclusión que, se dijo, fue uno de los factores generadores de esas violencias que sumergieron al país en un conflicto armado por más de medio siglo.

Pero ¿qué es lo alternativo y por qué es un camino hacia el buen vivir y la paz? Según Enrique Luengo González, lo alternativo son:

[...] las acciones y procesos impulsados por una pluralidad de colectivos ciudadanos, movimientos sociales o grupos étnicos que promueven posibles modos de vida y formas diversas de organización, diferentes a las impuestas por el sistema dominante neoliberal.

Las alternativas no son la solución de los problemas, sino vías posibles, caminos tentativos o exploraciones decididas por colectivos ciudadanos que pretenden respuestas para paliar o superar situaciones que les son adversas. En otras palabras, las alternativas son potencialidades, oportunidades, nuevas capacidades colectivas, o bien, propuestas emergentes de reorganización social. ${ }^{38}$

Fruto de las reflexiones sobre el tema, en la Universidad de Nariño se establece que lo alternativo es una apuesta diferente al modelo neoliberal que puso al ser humano en condición de objeto:

Lo alternativo: Frente al modelo actual centrado en la producción de medios, el crecimiento en la producción de los medios, el crecimiento de la producción de las cosas, proceso en el cual el ser humano adquiere también condiciones de objeto, se pasa a un nuevo modelo donde el fin absoluto de todos los procesos es el ser humano: su buen vivir. Esto implica su complejidad, el crecimiento integral: físico, mental, espiritual. No se trata de una propuesta para otros, sino para la propia Universidad. Es una Universidad Alternativa que, en su convivencia responsable, va contribuyendo a la construcción de la región alternativa. ${ }^{39}$

\footnotetext{
37 Plan de Desarrollo 2008-2020, "Pensar la Universidad y la Región”.

38 Enrique Luengo González, "Diversidad y dinamismo de las alternativas ciudadanas", en Las alternativas ciudadanas para otros mundos posibles: Pensamiento y experiencias, coord. E. Luengo González (Jalisco: ITESO, 2014), 13.

39 Universidad de Nariño, Cuadernos Universitarios de la Reforma No. 1. Principios y Agenda 2009 (San Juan de Pasto: Universidad de
} 
Es decir, lo alternativo está referido a un proyecto de universidad y región distinto al que propone el modelo neoliberal centrado en el capital y el mercado. La universidad entraña "un modelo donde el fin absoluto de todos los procesos es el ser humano: su buen vivir"; en suma, una universidad alterativa para la construcción de una región alternativa, pues "la Universidad se funde con la región", "Comparte con la región su saber y su producción científica y tecnológica y recibe el talento de su población, los saberes ancestrales, la solidaridad. La Universidad y la región se retroalimentan y crecen simultáneamente" ${ }^{\prime 4}$.

Pensar en desarrollo alternativo es un ejercicio de autonomía que aporta y potencializa el desarrollo social, cultural, científico, el buen vivir de los seres humanos, de las personas que viven en la región del sur occidente colombiano, dando así un giro y descentrando el concepto del plano económico y utilitarista.

El planteamiento de desarrollo alternativo propuesto en la misión de la Universidad de Nariño entraña un diálogo directo con la región, con lo local, es decir, con los seres humanos que la habitan, dialogar con sus saberes, reconocer y poner en valor sus cosmovisiones, conocer, apoyar y aportar a los proyectos de comunidad y sociedad que existan en este sur de Colombia, es por esto que una misión institucional que pretenda constituirse en una Universidad Alternativa para aportar a la construcción de una región alternativa es una ruta que conduce a la vida y a la paz.

He aquí un punto de quiebre frente a las propuestas eurocéntricas y estadocéntricas de modernidad, desarrollo, globalización. Pensar, investigar y enunciar que hay una región, que los desarrollos no se dan solo en sentido económico y de acumulación de capital, que por tanto pueden gestarse y desde el ejercicio misional de la universidad es factible apoyarse y aportar a "desarrollos alternativos", elemento fundamental para visibilizar aquello que desde el centro se ignoró deliberadamente hasta la década de los 90 del siglo XX y, que en el siglo XXI se pone en valor en función de volverlo mercancía y capital. La misión propuesta por la Universidad de Nariño es empezar a pensar en la posibilidad de construir una sociedad desde otros valores, desde otros símbolos, desde otras miradas, es aportar al tejido de lazos sociales que se destruyeron con el conflicto; en este sentido, el proponer en la Misión: "[...] formar seres Humanos, ciudadanos y profesionales en las diferentes áreas del saber y del conocimiento con fundamentos éticos y espíritu crítico para el desarrollo alternativo en el acontecimiento mundo", es formular una apuesta para el buen vivir y para la paz.

\section{Una universidad para la región, para la vida y la paz}

Pensar la región es una alternativa al modelo neoliberal, pues ésta no tiene lugar en la ciencia, en la educación, en la historia; la región no tiene derecho a hablar, a pensar, a proponer sus propias rutas de existencia; es decir, la región 
tiene sentido en función del orden nacional y global, en orden a una ciencia y epistemología que se otorgan a sí mismas el poder para definir y asumir lo que es verdadero y falso, pues:

\begin{abstract}
Por un lado, la epistemología pretendió configurar un lugar exterior respecto a todas las formas de conocimiento y prácticas de producción de conocimiento que le permitiese evaluarlas de manera independiente desde "fuera" o "por encima", reservándose para sí el derecho de juzgar su capacidad de distinguir entre la verdad y el error, así como el de definir los criterios de demarcación entre enunciados verdaderos y falsos... Sin embargo, por otra parte, mientras la epistemología postulaba la soberanía epistémica, tomaba como modelo una de las formas de conocimiento que se proponía evaluar: la ciencia. ${ }^{41}$
\end{abstract}

Frente a esta soberanía epistémica, en la Universidad de Nariño se levantan voces que desde el escenario de la Asamblea Universitaria se proponen pensar, debatir y, si es del caso, poner en cuestión el sistema de verdades planteado por la ciencia, especialmente, aquellas construcciones que tienen que ver con las teorías - mejor, doctrinas - del progreso, desarrollo, neoliberalismo, globalización, ciencia, conocimiento, con lo científico, para decirle a la nación y al mundo que aquí, en Nariño, se ejerce el derecho a pensar, a existir, a crear pensamiento respecto a la ciencia, la sociedad, la cultura, el desarrollo, o sobre las políticas del Estado colombiano en materia de educación superior.

El proceso de Reforma Universitaria llevado a cabo en el seno de la Asamblea Universitaria desde el año $2008^{42}$, con profundos debates, reflexiones y análisis que devienen en la construcción de este proyecto universitario, significa para los tecnócratas internos y externos a la Universidad de Nariño "un escándalo" y una "pérdida de tiempo"; pero para quienes, inmersos en el proceso, es apenas el inicio de un largo camino que busca emancipar el pensamiento, el conocimiento, la universidad de siglos del dominio epistémico occidental. Las bases puestas en el Proyecto Educativo Institucional, en el Plan de Desarrollo 20082020, "Pensar la Universidad y la Región" o en el Estatuto General, son algunos pasos dados en aras de construir una universidad que reconozca otras epistemologías y otras forma de habitar en la institución, para cumplir las funciones misionales de la docencia, la investigación y la interacción social, para que en su ejercicio reconozca no solo los saberes propuestos por la ciencia moderna sino también aquellos que se producen en la región del sur de Colombia, es decir incorpore los saberes alternativos, saberes propios que aporten a la construcción y existencia de una región alternativa.

El concepto de desarrollo alternativo que se estableció en la Misión Institucional y que inspirara el paradigma de "Universidad y Región" expuesto en el Plan de Desarrollo 2008-2020, "Pensar la Universidad y Región”, entraña la

\footnotetext{
41 João Arriscado Nunes, "El rescate de la Epistemología" en Epistemologías del Sur (Perspectivas), eds. Boaventura de Sousa Santos y María Paula Meneses (España: Akal, 2014), 221-222.

42 Erazo Coral, "Nuevos sentidos".
} 
necesidad de poner la mirada en lo local y regional para pensar en un mundo más justo, equitativo y plural:

El acontecimiento del mundo contemporáneo muestra la necesidad de afirmación de lo local y regional para que lo universal tenga sentido en la tarea de pensar un mundo justo, equitativo, plural y para que sea habitado más allá de la tecnofascinación en el ejercicio del poder, de la locura consumista en la producción material, de la precariedad significativa en la comunicación y lejos de la pretensión que idolatra una historia sin sujetos.

Nos entendemos menos en el relato universal porque desde pequeñas historias cubrimos los olvidos de la pretensión de totalidad. Hoy fracasa la dictadura del mercado y acude a pedirle una mano al Estado que amparó esa racionalidad económica entendida como desarrollo cuando en el siglo XVIII empieza a tomar forma la modernidad. ${ }^{43}$

De este modo, pensar en una universidad que dé respuesta a los problemas de región contraviene el proyecto de educación superior pensado en los centros de poder del Estado colombiano, más cuando esa mirada hegemónica y homogenizaste generada hasta la década de los 90 del siglo XX ocultó la diversidad cultural, social, económica, política, religiosa que existe en nuestro país y en la misma región sur occidental colombiana, integrada por subregiones como la pacífica, la andina y la amazónica - ¡cuánta diversidad entraña esta región!-, diversidad que en el siglo XXI, tiempo de neoliberalismo, se pretende valorizarla en función del capital y el mercado; ocultamiento y visibilización de la región desde los centros de poder, son dos caras de una misma moneda.

Imagen 4. Una región diversa ${ }^{44}$

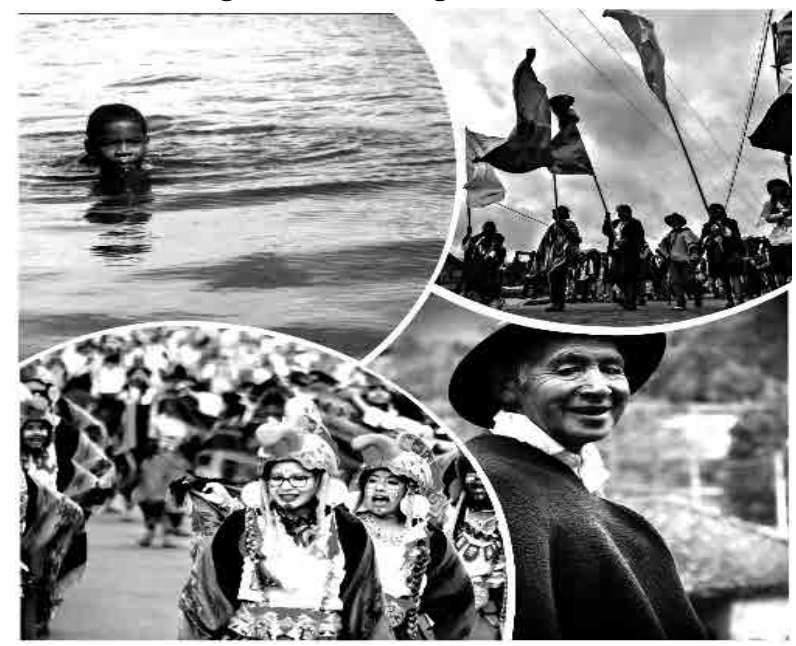

Fuente: Iván Darío Tobar, archivo personal.

43 Plan de Desarrollo 2008-2020, "Pensar la Universidad y la Región".

44 Collage fotográfico de Nariño: El Encano - Aldana - Pasto - Tumaco. 
Reconocer la dignidad y validez de todos los saberes implica que ninguno podrá ser descalificado sin poner a prueba su pertinencia y validez en condiciones situadas. Por el contrario, no debe concederse a ninguna forma de saber o conocimiento el privilegio de ser considerada más adecuada o válida que otras sin someterla a esas condiciones y ser evaluada por sus consecuencias o efectos. De este modo, ningún saber podrá ser elevado a la categoría de norma para evaluar la validez de otros saberes sin tener en cuenta las condiciones situadas de su producción y movilización, así como sus consecuencias. Las operaciones de validación de los saberes derivan, por tanto, de la consideración situada en la relación entre ellos configurando una ecología de saberes. Dado que la "ecología de saberes" no concibe los conocimientos en abstracto, sino como prácticas de saberes que permiten o impiden ciertas intervenciones en el mundo real, Santos caracteriza su posición como un "pragmatismo epistemológico", "justificado [ante todo] porque las experiencias vitales de los oprimidos son primariamente hechas inteligibles para ellos como una epistemología de las consecuencias", ya que, "en el mundo en que viven las consecuencias son primero, las causas después". ${ }^{45}$

El paradigma Universidad y Región indica que la universidad no está por fuera de la región, sino que hace parte de esta; en otras palabras, que la Universidad de Nariño es región.

Hemos entendido la Institución en convivencia responsable con la región, lo cual significa compartir con la comunidad sus saberes en los diferentes campos $y$, al tiempo, aprender de ésta, de sus diferentes cosmovisiones, de su multiculturalidad. Se trata de la construcción conjunta de un desarrollo regional alternativo. ${ }^{46}$

Conocer los contextos en los que la Universidad de Nariño ejerce su tarea, es fundamental; por eso, una de las reflexiones profundas que se dan en el seno de la Asamblea Universitaria es pensar el contexto en el que actúa:

La Universidad de Nariño está ubicada en un lugar estratégico del sur de Colombia, lo cual representa ventajas que posibilitan establecer la relación Universidad-Región. Una región multicultural, donde confluyen el Pacífico bio-geográfico, la Amazonía y los Andes, que la sitúan como frontera internacional de Colombia con Suramérica. Además, la riqueza natural del Departamento, representada en la hidrografía, la vegetación, la fauna, la mineralogía y el paisaje, características del complejo montañoso, de las costas, de las planicies, hacen de éste un lugar privilegiado frente a otros del mundo. ${ }^{47}$

Es decir, observa la diversidad como una potencialidad, no como un problema; esa diversidad que justifica el sueño de aportar como formadora de seres humanos, ciudadanos y profesionales; a pensar que otras formas de existencia, de proyectos de vida, otras racionalidades distintas a las planteadas

45 Arriscado Nunes, "El rescate de la Epistemología”, 25.

46 Plan de Desarrollo 2008-2020, "Pensar la Universidad y la Región”.

47 Acuerdo n. ${ }^{\circ} 035$ de 15 de marzo de 2013. 
por los centros de poder son posibles. Por eso, propone en su misión que esos hombres y mujeres formados en la Universidad de Nariño deben aportar a la creación de desarrollo alternativo, pues justamente la propuesta del Estado de plantear una sola vía del desarrollo, la económica, la del mercado, la del capital, es una de las mayores causantes de esas múltiples violencias que se viven en Colombia y que en las últimas décadas se siente con mayor rigor en el Sur de Colombia.

En Colombia existen varios factores que han contribuido a la profundización de las desigualdades sociales, a los desequilibrios ambientales, al aumento de la brecha tecnológica, al auge de la violencia y al conflicto social armado. Desde una visión alternativa, la academia, los avances científicos y tecnológicos y su internacionalización contribuyen a enfrentar la problemática ambiental, la búsqueda de soberanía alimentaria, el fortalecimiento de las identidades culturales, la solución negociada y razonada de los conflictos, la creación y la adopción de tecnologías limpias para impulsar la conservación y el uso sostenible de los recursos naturales. ${ }^{48}$

Es decir, frente a esas desigualdades sociales, desequilibrios ambientales, aumento de la brecha tecnológica, al auge de la violencia y al conflicto social armado, la universidad puede cumplir su papel desde una "visión alternativa", aportando, entre otras, a la "solución negociada y razonada de los conflictos"; por eso, en concordancia con lo planteado en su Misión, su Visión, manifiesta:

La Universidad de Nariño, entendida como un acontecimiento en la cultura, es reconocida por su contribución, desde la creación de valores humanos, a la paz, la convivencia, la justicia social y a la formación académica e investigativa, comprometida con el desarrollo regional en la dimensión intercultural. ${ }^{49}$

Como se puede ver, la contribución a la paz es uno de sus compromisos. En un país donde el Estado pretendió construir una nación homogénea, pensar en la pluralidad y responsabilidad social como principios es fundamental para tejer caminos que puedan, un día no muy lejano, permitir vivir a los colombianos, y a los nariñenses, en una sociedad con equidad y justicia social, elementos fundamentales para la vida y para generar tejidos de paz. En tal sentido, uno de los principios de la universidad es actuar con "pertinencia y responsabilidad social", entendidos:

[...] desde la perspectiva del conocimiento y el mejoramiento constantes, para estudiar la realidad, proponer planes de prevención y alternativas de solución a las problemáticas, en retroalimentación mutua, en pro de la vida; para la construcción social de las ciencias y para el ejercicio de acciones que promuevan al ser humano y a la sociedad en armonía con la naturaleza.

48 Ibíd.

49 Ibíd., 20. 
La Universidad, a través de la investigación, tiene la responsabilidad de promover la innovación, la creación y la apropiación social del conocimiento al servicio de la vida. En el ejercicio de su interacción social, tiene el compromiso de realizar acciones académicas de articulación sustentables con el entorno natural, dentro del contexto social y general, conducentes a mejorar las condiciones de vida en todas sus manifestaciones y potenciar las oportunidades, las fortalezas y los aspectos positivos que poseen las comunidades. ${ }^{50}$

Es decir, la docencia, la investigación y la interacción social tienen un propósito: la vidA, esa que la violencia arrebata con tanto cinismo, esa que por más de cincuenta años de guerra vividos en medio de la zozobra, de la angustia, del odio, del miedo, ha sido menoscabada en su posibilidad de disfrute; violencia que a su paso deja huérfanos, viudas, desterrados, que permitió, y permite, justificar las injusticias, la corrupción, la violencia de Estado, esa que no permite expresar con libertad diferencias políticas, religiosas e ideológicas, que acabó incluso con expresiones culturales. Por eso el compromiso de la Universidad de Nariño es con la paz, es decir, con una educación por y para la vida.

La lectura de los documentos producidos en el proceso de Reforma Profunda y de los que ya fueron elevados a normas institucionales a través de Acuerdos del Honorable Consejo Superior ${ }^{51}$ permiten evidenciar que, cuando la universidad se refiere a "la VIDA", lo hace no solo desde la mera existencia biológica, ni articulándola con la visión mercantilista y consumista. El concepto de vIDA está planteado como el derecho a existir desde el mundo simbólico, cultural, ideológico, político, espiritual, en proyectos de relación hombre-naturaleza. También la vida se la entiende como el derecho a la autodeterminación, es decir, al derecho del pensamiento propio, a la construcción de múltiples proyectos de existencia, al derecho a construir utopías; la vida también se articula a la justicia social; la vIDA, igualmente, queda vinculada al derecho del buen-vivir, concepto que se retoma de las cosmovisiones ancestrales de pueblos que habitan no solo este sur de Colombia, sino de América Latina.

[...] es el Buen vivir el que permite consolidar ese ejercicio, como una práctica heredada de los ancestros de América, edificando y proponiendo una nueva alternativa de los modelos sociales, políticos y culturales que dan lugar al cuidado del ser y el estar, y no solo del sobrevivir que es una hostilidad que desde Europa se plantea. Por tal motivo, es adecuado articular dichos procedimientos para que los componentes de la educación y la educabilidad aporten para que la cultura de paz crezca en sana convivencia, en pro de una buena comunidad educativa [...].52

50 Ibíd., 21-22.

51 Acuerdos emanados por el Honorable Consejo Superior: Proyecto Educativo Institucional PEI, Acuerdo n. ${ }^{\circ} 035$ de 15 de marzo de 2013; Plan de Desarrollo 2008-2020, "Pensar la Universidad y la Región", Acuerdo n. ${ }^{\circ} 108$ de 17 de diciembre de 2008 y Estatuto General de la Universidad de Nariño, Acuerdo n. ${ }^{\circ} 080$ de 23 de diciembre 2019.

52 Víctor Javier Erazo Pantoja y César Eliécer Villota Eraso, Por los caminos del Buen Vivir. El andar de la paz en el desandar de la violencia: Cátedra de la paz y el Buen Vivir (San Juan de Pasto: IEM Luis Eduardo Mora Osejo, 2019), 165. 
Por su parte, la Universidad de Nariño define su propia visión sobre lo que es el buen vivir, y la articula con la autoderminación, con la justicia social, con la relación hombre-naturaleza, con una cosmovisión compleja y propia, propia de seres humanos solidarios y respetuosos del otro, de la diferencia que aporte para crear condiciones de equidad e igualdad.

\begin{abstract}
En un proceso de pensamiento e imaginación complejo y democrático se han dado pasos importantes hacia la construcción teórica de un sueño de bienvivir en una REGIÓN CON AUTODETERMINACIÓN Y JUSTICIA SOCIAL, entendida COMo un espacio humano-natural, que posee una cosmovisión compleja que se comprende, se reconoce y se autorregula, que está en permanente cambio, en interacción con otros ámbitos de realidad; con seres humanos solidarios capaces de entender y respetar al otro como igual y diferente, que genera condiciones de equidad y libertad.

La Universidad está llamada a encontrar en el convulsionado mundo de hoy, de múltiples crisis interrelacionadas, las oportunidades para construir futuros mejores. Ya podemos afirmar que contamos con atisbos de espacios que se abren hacia la construcción del sueño. ${ }^{53}$
\end{abstract}

Este planteamiento en el Plan de Desarrollo 2008-2020, “Pensar la Universidad y la Región", ratificado en la misión y visión institucional, le dice a Colombia y al mundo que esta universidad se aleja de los propósitos eurocéntricos de poner esta institución al servicio del capital y el mercado. Esta universidad se piensa, existe para responder a las necesidades de la región; esta universidad existe para establecer un diálogo directo con esos seres humanos, hombres y mujeres que en ella habitan: existe para valorar sus saberes, para aprender de ellos, para poner aquello que el occidente llama "ciencia" al servicio de la resolución de los problemas que aquejan al sur occidente colombiano; esta universidad existe para aportar al "sueño de bienvivir en una REGión CON AUTODETERMINACIóN Y Justicia social", así está escrito, con mayúsculas, en el Plan de Desarrollo. Esta Universidad de Nariño entonces es una apuesta por y para la vida y la paz de la región sur y de Colombia.

\title{
CONCLUSIÓN
}

La universidad como institución tiene sus fundamentos epistemológicos y científicos en la lógica eurocéntrica y estadocéntrica, y desde esta episteme sirve a los propósitos de los centros de poder, al mercado y al capital, aspecto que es una de las causas de las violencias que por más de medio siglo se viven en Colombia. Por tal razón, entre las tareas que debe asumir la comunidad universitaria están las de reflexionar, debatir y construir nuevas lógicas para habitar la universidad, más en regiones como la nariñense que actúa en un contexto de diversidades culturales, sociales, ambientales, geográficas, que son invisibi-

53 Plan de Desarrollo 2008-2020, "Pensar la Universidad y la Región". 
lizadas por la soberanía epistémica occidental. El reto se asume en el espacio de la Asamblea Universitaria de la Universidad de Nariño, lugar desde donde se plantea un proyecto de universidad que le sirva y aporte a la resolución de los problemas regionales de los hombres y mujeres que habitan este sur de Colombia.

Se propone entonces un nuevo paradigma: el de Universidad y Región, y nuevas categorías de pensamiento como la de desarrollo alternativo que sitúa a la región como centro de análisis y acción de la institución, entendiendo de este modo que la universidad es región; a partir de allí busca hacer visible todo aquello que desde los centros de poder se excluyó, se negó e invisibilizó, se asume la diferencia como un potencial para nuevos proyectos de desarrollo regional alternativos, aspecto fundamental para reconstruir tejidos sociales que las violencias destruyeron.

El planteamiento de desarrollo alternativo propuesto en la misión de la universidad entraña poner a la universidad en un diálogo directo con la región, con lo local, es decir, con los seres humanos que la habitan, dialogar con sus saberes, reconocer y poner en valor sus cosmovisiones, conocer, apoyar y aportar a los proyectos de comunidad y sociedad que existan en este sur de Colombia; es por esto que una misión institucional que pretenda constituirse en una Universidad Alternativa para aportar a la construcción de una Región Alternativa es una ruta que conduce a la vida y a la paz.

La vida, desde la perspectiva de la institución de educación superior, no está referida a la mera existencia biológica. La vida a la que se refiere el proyecto universitario se inscribe en la perspectiva del "Buen Vivir", que entraña lo simbólico, cultural, social, político, la relación hombre-naturaleza, la visión milenaria de las culturas ancestrales de este sur de Colombia y de América Latina.

Pensar en desarrollo alternativo es un ejercicio de autonomía que aporta y potencializa el desarrollo social, cultural, científico, el buen vivir de los seres humanos, de las personas que viven en la región del sur occidente colombiano, dando así un giro y descentrando el concepto "desarrollo" del plano económico y utilitarista.

Este proyecto de universidad se expresa en la misión y visión de manera contundente: esta universidad no estará al servicio del capital y el mercado, sino para aportar a los campesinos, indígenas, afrodescendientes, a los hombres y mujeres que habitan esta región sur occidente de Colombia, la institución existe para valorar y conversar con los saberes construidos centenariamente por sus habitantes y por tanto para aprender de ellos; está para producir ciencia al servicio de la región; en fin, la Universidad de Nariño ejerce sus funciones misionales para aportar al bien vivir, a la autodeterminación de esta región, a la justicia social; es por todo esto que la Universidad de Nariño construye una misión y visión que es una apuesta por y para la vida y la paz. 


\section{FUENTES}

Acuerdo 079 de 30 de noviembre de 2010. Por el cual se adopta la Reforma Universitaria como una política académicoadministrativa institucional, para dar cumplimiento al Plan de Desarrollo de la Universidad de Nariño 2008-2020, "Pensar la Universidad y la Región". San Juan de Pasto: Universidad de Nariño, 2010.

Acuerdo n. ${ }^{\circ} 035$ de 15 de marzo de 2013. Por el cual se adopta el Proyecto Educativo Institucional (PEI) de la Universidad de Nariño. San Juan de Pasto: Universidad de Nariño, 2013.

Acuerdo 080 del 23 de diciembre de 2019. Por el cual se adopta el Estatuto General de la Universidad de Nariño. San Juan de Pasto: Universidad de Nariño, 2019.

Acuerdo n. ${ }^{\circ} 2034$ de 2014 o la Ley de Inspección y Vigilancia de 2015, Decreto 2450 de 2015. Políticas de COLCIENCIAS para la Investigación y Evaluación de Investigadores, Libros y revistas. Políticas del Consejo Nacional de Acreditación. Bogotá: Consejo Nacional de Educación Superior, 2014. https://www.mineducacion.gov.co/1621/articles-344500_archivopdf_sintesi_doc_acuerdosuperior.pdf. (7/3/2020).

\section{REFERENCIAS}

Arriscado Nunes, João. "El rescate de la Epistemología". En Epistemologías del Sur (Perspectivas), editado por Boaventura de Sousa Santos y María Paula Meneses. España: Akal, 2014.

Bourdieu, Pierre y Loïc Wacquant. Las argucias de la razón imperialista. Barcelona: Paidós, 2001.

De Sousa Santos, Boaventura. La Universidad en el siglo XXI para una reforma democrática y emancipatoria de la universidad. La Paz: Plural Editores, 2007.

"Declaración de Bolonia”. Declaración conjunta de los ministros europeos de Educación (Bolonia, 19 de junio de 1999), http://eees.umh.es/contenidos/Documentos/DeclaracionBolonia.pdf. $(3 / 7 / 2020)$.

Erazo Coral, María Elena. “Nuevos sentidos de la Reforma de Córdoba: El caso de la Universidad de Nariño". Revista Historia de la Educación Latinoamericana 20, n. ${ }^{\circ} 30$ (2018): 67-83.

Erazo Pantoja, Víctor Javier y César Eliécer Villota Erazo. Por los caminos del Buen Vivir. El andar de la paz en el desandar de la violencia: Cátedra de la paz y el Buen Vivir". San Juan de Pasto: IEM Luis Eduardo Mora Osejo, 2019.

Escobar V., Arturo. La invención del Tercer Mundo. Construcción y deconstrucción del desarrollo". Bogotá: Grupo Editorial Norma, 1998.

Henao, Hernán. "La dimensión cultural en los estudios de las localidades". En La restructuración de las ciencias sociales en América Latina, editado por Santiago Castro Gómez. Bogotá: Centro Editorial Javeriano, 2000.

Luengo González, Enrique. “Diversidad y dinamismo de las alternativas ciudadanas”. En Las alternativas ciudadanas para otros mundos posibles: Pensamiento y experiencias, coordinado por E. Luengo González. Jalisco: ITESO, 2014.

Erazo Coral, María Elena, “Nuevos sentidos de la Reforma de Córdoba: El caso de la Universidad de Nariño", Revista Historia de la Educación Latinoamericana 20, n. ${ }^{\circ} 30$ (2018): 74-75.

Paz Maldonado, Eddy Javier y Wilmer Nahán Díaz Pérez,. “Educación para la paz: Una mirada desde la Universidad Nacional Autónoma de Honduras", Innovación educativa 19, n. ${ }^{\circ} 79$ (2019): 171-195.". http://www.scielo.org.mx/scielo.php?script=sci_abstract\&pi$d=S 1665-26732019000100171 \& \operatorname{lng}=e s \& n r m=i s o \& t \operatorname{lng}=e s(5 / 7 / 2020)$.

Presidencia de la República de Colombia. "Acuerdo final para la terminación del conflicto y la construcción de una paz estable y duradera". (La Habana, 2016). https://www.cancilleria. gov.co/sites/default/files/Fotos2016/12.11_1.2016nuevoacuerdofinal.pdf. (10/10/2018).

Quijano, Aníbal. "Colonialidad del poder y clasificación social". En Epistemologías del Sur (Perspectivas), editado por Boaventura de Sousa Santos y María Paula Meneses. España: Akal, 2014, 67-107.

Rincón Bolívar, Carlos. La no simultaneidad de lo simultáneo. Posmodernidad, globalización y culturas en 
América Latina. Bogotá: Universidad Nacional de Colombia, 1995.

Ruiz, Jorge Eliécer. "Crítica de la universidad". ECO. Revista de la cultura de Occidente 12-3, n. ${ }^{\circ} 69$ (1966): 257-258.

Samacá, Gabriel David y Álvaro Acevedo Tarazona, “De la reforma de Córdoba al Cordobazo. La universidad como escenario de las luchas por la democracia en Argentina 1918-1969 y su impacto en Colombia", Memorias, n. ${ }^{\circ} 15$ (2011): 170-190.

Universidad de Nariño. Cuadernos Universitarios de la Reforma No. 1. Principios y Agenda 2009. San Juan de Pasto: Universidad de Nariño, 2009.

Universidad de Nariño, Plan de Desarrollo 2008-2020. "Pensar la Universidad y la Región". San Juan de Pasto, 2009.

Wallerstein, Immanuel, coordinador. Abrir las ciencias sociales. Informe de la Comisión Gulbenkian para la restructuración de las ciencias sociales. México: Siglo Veintiuno Editores / UNAM, 2007.

\section{Cómo citar:}

Erazo Coral, María Elena. “El desarrollo alternativo: misión de la Universidad de Nariño para la vida y la paz". Revista Historia de la

Educación Latinoamericana. 22 No. 35 (2020): 229-252

DOI: https://doi.org/10.19053/01227238.11958

(c) $\mathbb{0} \Theta \Theta$ Esta obra está bajo una licencia Creative Commons. Reconocimiento-No Comercial-Sin Obra Derivada 2.5 Colombia. 